\title{
Optimization of Operating Ozone-Activated Carbon on Advanced Water Treatment Processes
}

\author{
Seongtae Park ${ }^{1}$, Hoe-Suk Jung ${ }^{1}$, Ihnsup Han ${ }^{1}$, Jungyeol Eom ${ }^{2}$, Heekyong Oh$^{2}$ \\ ${ }^{1}$ Department of Environmental Engineering, University of Seoul \\ 163 siripdae-ro, Dongdaemun-gu \\ Seoul, Korea \\ tjdxocom124@naver.com; hoesuk.jung@gmail.com; ishan@uos.ac.kr \\ ${ }^{2}$ Plant \& Environment Research Team, Daewoo E\&C \\ 20, Suil-ro, 123beon-gil, Jangan-gu, Suwon-si \\ Gyeonggi-do, Korea \\ jungyeol.eom@daewooenc.com; heekyong.oh@daewooenc.com
}

\section{Extended Abstract}

Advanced water treatment means a process where "ozone + activated carbon process" is added to the conventional water treatment process by a plant introduced in order to remove taste \& odor causing materials (Geosmin, 2-MIB), natural organic matter (NOM), and so on ${ }^{1), 2)}$. In Seoul city, with regard to the advanced water treatment plant, "postozonation+BAC" advanced water treatment system was first introduced to Y water treatment plant in October 2010. However, the actual condition is that operation knowhow is still insufficient. Therefore, in this study, pilot plant with the capacity of $25 \mathrm{~m}^{3} /$ day(Sand Filter water) was installed at Y water treatment plant, and a study on optimizing the operation of ozone + activated carbon unit process was carried out.

Treatment process is composed of Sand Filter Water - Ozone Contact $-\mathrm{H}_{2} \mathrm{O}_{2}$ Quenching - Biological Activate Carbon - Drinking Water.

For the optimal operation of ozone + activated carbon process, the following results were produced.

1. In order to maintain $0.05 \mathrm{mg} / \mathrm{L}$ of residual ozone concentration in ozone contact tank outlet, ozone was injected into each unit process by using side steam. Dose depended on water temperature when ozone was injected ${ }^{3)}$. Ozone of $0.30(0.14 \sim 1.01) \mathrm{mg} / \mathrm{L}$ and $0.43(0.30 \sim 1.20) \mathrm{mg} / \mathrm{L}$ was injected in case of low water temperature $\left(1 \sim 10^{\circ} \mathrm{C}\right)$ and normal water temperature $\left(11 \sim 20^{\circ} \mathrm{C}\right)$ respectively. It is thought that this occurs as solubility decreases according to temperature. Besides, ozone was discharged when the concentration of ozone injected was $0.35 \mathrm{mg} / \mathrm{L}$ or above and when water temperature was $13^{\circ} \mathrm{C}$ or above.

2. $\mathrm{H}_{2} \mathrm{O}_{2}$ fed to remove ozone is fed in the ratio 1:4 in comparison with residual ozone during low water temperature season, and it was fed in the ratio 1:0.5 during normal temperature season. At that time, with regard to residual ozone concentration, $73 \%$ and $100 \%$ was removed. As a result, it can be found that residual ozone situation becoming a problem in "Ozone + BAC" process improves.

3. When the removal of organic matter through the above-mentioned process was examined, with regard to $\mathrm{KMnO}_{4}$ consumption, it was treated $(67.6 \%)$ with $1.45(0.24 \sim 2.29) \mathrm{mg} / \mathrm{L}$ in case of sand filtrate, $1.25(0.28 \sim 1.77) \mathrm{mg} / \mathrm{L}$ after ozonation, and $0.47(0.04 \sim 1.03) \mathrm{mg} / \mathrm{L}$ after BAC.

4. With regard to $\mathrm{UV}_{254}$ to measure aromatic compounds with double bonds, it was treated (78.9\%) at a level of $0.019(0.014 \sim 0.030) \mathrm{cm}^{-1}$ in case of sand filtrate, $0.008(0.003 \sim 0.014) \mathrm{cm}^{-1}$ after ozonation, and $0.004(0.001 \sim 0.010) \mathrm{cm}^{-1}$ after BAC.

5. With regard to $\mathrm{UV}_{260}$ to measure hydrophobic organic matter in natural organic matter (NOM), it was treated $(76.5 \%)$ at a level of $0.017(0.012 \sim 0.027) \mathrm{cm}^{-1}$ in case of sand filtrate, $0.007(0.001 \sim 0.013) \mathrm{cm}^{-1}$ after ozonation, and $0.004(0.001 \sim 0.009) \mathrm{cm}^{-1}$ after BAC. 
6. With regard to $\mathrm{UV}_{272}$ used as indicator of DBPs formation, it was treated (85.7\%) at a level of $0.014(0.010 \sim 0.016) \mathrm{cm}^{-1}$ in case of sand filtrate, $0.006(0.001 \sim 0.012) \mathrm{cm}^{-1}$ after ozonation, and $0.002(0.001 \sim 0.009) \mathrm{cm}^{-1}$ after BAC.

7. With regard to average removal efficiency after reaction with ozone in sand filtrate for 250 days, $16 \%$ of $\mathrm{KMnO}_{4}$, $10 \%$ of TOC and $12 \%$ of DOC was removed respectively. And with regard to $\mathrm{UV}_{254}$ and SUVA, it was shown that removal efficiency was 57\% and 51\% respectively. It seems that a decrease in the amount of UV after ozonation is caused by transformation due to oxidation, not complete removal of organic compounds having multiple bonds as organic matter is partially decomposed due to the oxidizing power of ozone. This reason can be checked by low removal efficiency of TOC, indicator of total amount of organic matter. It was shown that average removal efficiency in sand filtration+ $\mathrm{O}_{3}+\mathrm{BAC}$ process was definitely higher than in ozone-only process. With regard to average removal efficiency, $63 \%$ of $\mathrm{KMnO}_{4}, 64 \%$ of TOC and $65 \%$ of DOC was removed respectively. And it was shown that removal efficiency was $76 \%$ in $\mathrm{UV}_{254}$ and $30 \%$ in SUVA.

\section{Acknowledgements}

This subject is supported by Korea Ministry of Environment as "Global Top Project (2016002110001)"

\section{References}

[1] J. T. Ha, "Study on the applicability of the ozone / AOP and activated carbon process for the removal of trace organic contaminants and taste odor causing substances," Journal of Wetlands Research., vol. 17, no. 2, pp. 155-162, 2015.

[2] K. E. Yun, "Removal of Natural Organic Matter in Han River Water by GAC and O3/GAC," M. S. Thesis, Dept. Env. Eng., Univ. of Seoul., Seoul, Korea, 2008.

[3] M. H. Kwon, "Removal of residual ozone in drinking water treatment using hydrogen peroxide and sodium thiosulfate," Journal of Korean Society of Water and Wastewater, vol. 29, no. 4, pp. 481-491, 2015. 